\title{
ESCOLA E FAMÍLIA: O PROCESSO DE ESCOLARIZAÇÃo E A CONSTITUIÇÃO DA IDENTIDADE NA CONTEMPORANEIDADE
}

\author{
SCHOOL AND FAMILY: THE EDUCATION PROCESS AND THE \\ CONTEMPORARY IDENTITY BUILDING
}

\author{
Marcos Aurélio Barbai (Labeurb/UNICAMP)
}

\begin{abstract}
Resumo: O objetivo deste texto é refletir e analisar a relação entre escola e família, particularmente o processo de escolarização e de constituição da identidade na sociedade brasileira. A família e a escola são um interessante laboratório para se pensar, pela linguagem, o político, o social e o afetivo. Para isso, analisamos uma imagem, selecionada para divulgar um evento científico em educação, seguindo os pressupostos teóricos e metodológicos da Análise de Discurso. A imagem, um forte e poderoso operador de memória, é um suporte material importante para se pensar os sentidos de sociedade, de escrita, de autoria e de subjetividade.
\end{abstract}

Palavras-chave: Processo de escolarização. Escola. Família. Imagem. Discurso.

Abstract: This paper aims to reflect and analyze the relation between school and family, particularly the education process and building of the identity in the Brazilian society. The family and the school are an interesting laboratory to observe, by the language, the political, the social and the affective. In order to do it, we analyzed an image selected to publicize a scientific event in education, starting to the theoretical and methodological assumptions from Speech Analysis. The image, like a high and powerful memory operator, is a relevant material support to think senses of society, write, authorship and subjectivity.

Keywords: education process. School. family. Image. speech.

Este texto toma como lugar de reflexão a temática "Escola e família: implicações sociais" proposta de trabalho do VII Seminário em Educação e III Colóquio de Pesquisa, realizado pela UEMS de Paranaíba, em 2010. Estabeleço como material de análise, de modo a discutir essa temática, três imagens: a imagem de um cartaz confeccionado para divulgar um evento científico, uma propaganda veiculada em um jornal de circulação nacional e a cena de um filme (a imagem em movimento) detendo-me no diálogo entre personagens.

Para além da dicotomia verbal/não verbal, tão presente nos estudos da linguagem, quando se fala em análise de imagem, considero esta materialidade um "operador da memória social” (cf. PÊCHEUX, p. 51). Ela é, portanto, uma ordem ${ }^{l}$ significante em relação à evidência dos sentidos que ali se sedimentam. A imagem é fato do visível que reclama sentido e demanda interpretação.

\footnotetext{
${ }^{1}$ Ordem no sentido que lhe dá Foucault em A ordem do discurso. Ver: FOUCAULT, M. A ordem do discurso: aula inaugural no College de France, pronunciada em 2 de dezembro de 1970. Tradução Laura F. de Almeida Sampaio. 2. ed. São Paulo: Loyola, 1996.
}

\begin{tabular}{|l|l|c|c|c|c|}
\hline Interfaces da Educ. & Paranaíba & v. 2 & n. 5 & p.5-23 & 2011 \\
\hline
\end{tabular}




\section{INTERFACES DA EDUCAÇÃO}

$\mathrm{O}$ acontecimento ${ }^{2}$ que produz esse texto é um convite para ministrar uma palestra em um evento científico, o que faz minha escrita ser atravessada pela voz, pelo oral em gesto. $\mathrm{O}$ meu objetivo é pensar, da perspectiva do processo de identificação, tendo em vista a materialidade da imagem, o processo de escolarização, os laços entre escola e família e os efeitos desse enlaçamento no que diz respeito à educação, na sociedade brasileira.

O que sustenta essa reflexão é a leitura que faço do processo de escolarização: marca da letra no corpo da cidade, no corpo do sujeito, haja vista que somos uma sociedade urbana pautada pela escrita. Levo fundamentalmente em consideração o fato de que somos sujeitos de linguagem. A escola e a família, enquanto um espaço histórico e social, que une sujeitos, é um laboratório interessante para ser ver a linguagem em vida.

Enquanto a psicologia vê a cria humana como um ser que vai se desenvolver segundo estágios lógicos e interacionais, dirigidos pela ordem biológica e social, vejo (e aqui entra particularmente a linguagem) o sujeito como incompleto, como uma falta a ser. O sujeito se constitui pela e na materialidade da língua (cf. ORLANDI, 1999; 2001), se filiando a sentidos. Como diz Revuz (2002, p. 26), “[...] eu sou a maneira como fui investido pela fala daqueles que colocaram em palavras, as suas palavras, sobre minhas emoções, sobre meus primeiros sofrimentos e prazeres".

O feto, o bebê e cada um de nós se movem na linguagem. Quando nascemos os discursos já estão em circulação, e entramos nessa instância. É nesse lugar de ter sido posto em palavras, antes de ter sido posto no mundo, que a linguagem investe o corpo do sujeito, podendo este viver e significar no mundo, esse espaço de todos os fenômenos.

A língua, enquanto um saber, tem na família uma primeira instância de aquisição. $\mathrm{Na}$ escola a criança vai encontrar um outro saber sobre a língua, acompanhado de outras exigências. Seja a língua nosso objeto de paixão ou objeto de contenda e de luta, uma questão é incontornável: a nossa sociedade urbana é atravessada pela língua escrita.

É aqui, a meu ver, que o processo de escolarização toma corpo. Vamos à escola porque alguma coisa falta. Se a família nos dá, por conta da filiação, um nome, uma relação consanguínea e o estatuto de sujeito (sujeito civil para o Estado), para viver em sociedade é necessário um outro estatuto: o da cidadania.

A escola é, portanto, esse lugar que "se coloca na responsabilidade de produzir a consciência da língua ${ }^{3}$ e da cidadania no aluno que ainda se encontra como 'cidadão e autor em embrião', trabalhando no nível da organização administrativa [...] de um sujeito urbano escolarizado" (cf. PFEIFER, 2003, p. 117). A escola, diz a autora, produz uma língua já pronta para seus alunos assim como uma cidade já pronta.

Assim, escola e família se ligam perpetuamente como instâncias responsáveis pela educação dos sujeitos. É impossível pensar a "educação" sem a família e sem a escola. Mesmo que a forma do "educar" seja diferente, elas são instituições encarregadas de guardar os filhos (os filhos da nação) e de moldar o futuro.

Para refletir sobre essa ligação, sobretudo o problema que essa ligação coloca, é que escolhi como material de análise a imagem. Os sentidos que partilhamos socialmente de

\footnotetext{
${ }^{2}$ Considero acontecimento no sentido que lhe dá Michel Pêcheux ponto de encontro de atualidade e uma memória. Ver PÊCHEUX, M. Discurso: estrutura ou acontecimento. Trad. Eni P. Orlandi. Campinas: Pontes Ediotres, 1990.

3 Aqueles que não aprenderam a escrita de uma língua (tratada muitas vezes como uma ferramenta de comunicação), que não foram alfabetizados (o domínio da leitura), portanto um ser analfabeto, a não escolarização significa muito mais. Trata-se, como diz Silva (1998, p. 25), uma coisa herdada "analfabeto de pai e mãe".
}

\begin{tabular}{|l|l|l|l|l|l|}
\hline Interfaces da Educ. & Paranaíba & v. 2 & n. 5 & p.5-23 & 2011
\end{tabular}


escola e de família, no que diz respeito à educação, não nascem do nada. Há o trabalho da memória discursiva, fazendo falar (e também ver) um saber independentemente do sujeito.

Somos tomados pela ilusão da completude da imagem, que representa muitas vezes coisas e pessoas, materializando (como se fosse possível) um reflexo do real e constituindo uma identidade no mundo. No solo pragmático, a identidade e a identificação são concebidas como topos (o lugar) de manifestações de um sujeito da representação e de um estatuto desse representante. Esses mecanismos, considerados como lugar de evocação de uma presença, faz com que a identificação seja um constante movimento de uma imagem individual (aberta à multiplicidade) e a identidade, uma marca, um caráter formal (fixo) da imagem.

O que pretendo fazer trabalhar é a desestabilização do fixo de uma imagem, a representação daquilo que ela oferece a ver. Isso, porque a identidade (e penso aqui naquilo que faz presença quando se fala em escola e família) é movimento na história. E quando há movimento a similitude, a semelhança é uma ilusão. Há falta. E esta não é defeito face aquilo que, atravessado pelo imaginário, se oferece como consistente.

Assim, proponho como primeiro gesto de análise a leitura do cartaz ${ }^{4}$ deste evento. Considero este uma imagem que, em sua condição constitutiva, é lugar de construção do sentido, muito mais que um simples "se dar a ver", convidar ou divulgar um evento. O cartaz ao funcionar como um operador de memória me autoriza a trabalhar com a contradição que torna escola e família materialidades da educação.

A contradição permite-me ainda deslocar a leitura em que comumente a questão da identidade é articulada, ou seja, lugar de manifestação da representação, estatuto de um representante, propriedade reflexiva de um elemento. $\mathrm{O}$ fenômeno da identidade não meramente reflexivo e representativo. Se assim o fosse não haveria a oposição, o negativo. Nessa direção, a contradição (a impossibilidade do idêntico) ficaria apagada, denegada.

A escola e a família, corpos singulares e também institucionais não são homônimos ${ }^{5}$ no que diz respeito à educação. Elas são entre si o unheimlich $^{6}$ (o estranho-familiar) para lembrar uma expressão de Freud. O Unheimlich, uma imagem estranha que provoca ao mesmo tempo desconforto e familiaridade, é como um segredo que se revelou ou emergiu. $\mathrm{Na}$ reflexão que aqui empreendo, chamar escola e família de unhemlich (no que se refere à educação) significa dizer que há uma discrepância entre elas. São instituições que se ligam por certa familiaridade (como não lembrar aqui o título de um importante livro de Paulo Freire - Professor Sim, Tia Não!), mas ao mesmo tempo estranhas e insuportáveis quando em relação.

Partindo do pressuposto de que o sentido é janela de que se olha, e tendo por objetivo problematizar aquilo que se visualiza, ou seja, a totalidade que abrange e é abrangida pelo

\footnotetext{
${ }^{4}$ Escolhi essa imagem por dois motivos: o primeiro deles diz respeito à beleza plástica da imagem; já o segundo o trabalho que desenvolvo pensando as relações entre discurso e imagem. Assim, a imagem é lida como um objeto semântico, já que o sujeito, ou seja, cada de um nós, é afetado por aquilo que vê. Sobre essas questões ver BARBAI, M. A. Ver no já visto: imagem e filiação. In: Scherer, A. E; PETRI, V.; DIAS, C. (Org.) Tecnologia de Linguagem e Produção do Conhecimento. Livro Digital, Volume II, Coleção HiperS@beres, 2010. Disponível em: http://www.ufsm.br/corpus.

${ }^{5}$ Trago a questão da homonímia para problematizar o lugar que tem escola e família, cada uma, face à educação. A homonímia (mesma forma fonológica, categorial e lexical - por exemplo, "manga": fruta, nome que designa a parte de uma vestimenta, roupa) é polissêmica. Por isso, é algo aberto à equivocidade. Tomo assim a educação como lugar material homônimo que une dois antônimos (escola e família). Ao invés de haver aí unidade (portanto identidade entre escola e família, univocidade) há equivocidade. Está aí o princípio da contradição: há disjunção.

${ }^{6}$ Unheimlich (a estranheza-familiar) é uma palavra que dá nome a um texto de Freud (Das Unheimlich - O Estranho, Standart Edição Brasileira, Imago, vol. XVII).
}

\begin{tabular}{|l|l|l|l|l|l|}
\hline Interfaces da Educ. & Paranaíba & v. 2 & n. 5 & p.5-23 & 2011 \\
\hline
\end{tabular}




\section{INTERFACES DA EDUCAÇÃO}

olhar, um olhar organizado e organizador de uma totalidade (cf. ORLANDI, 2004, p. 29) este cartaz que se segue, e com algumas modificações, surge como um acontecimento a ler, em uma leitura que deve considerar a condição do legível em relação ao próprio legível (cf. PÊCHEUX, 1999, p. 52).

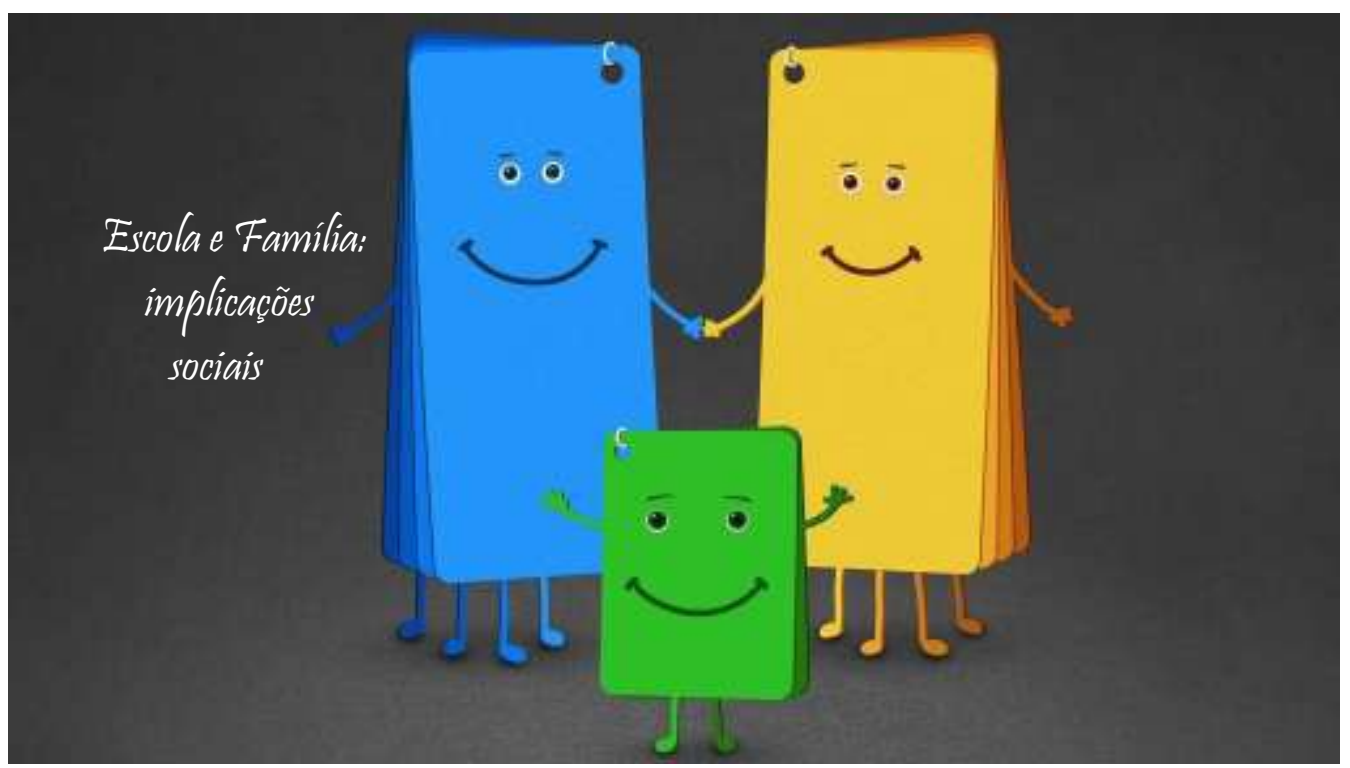

Assim, trabalhando com os efeitos de pré-construído, isto é, os efeitos do já-dito (e, acrescento, do já-visto), "aquilo que remete a uma construção anterior, exterior, em todo caso independente por oposição ao que é 'construído' pelo enunciado" (PÊCHEUX, 1988, p. 88-89), há um conjunto de elementos que aparecem na imagem como sempre estivessem sempre ali, (mostrando que há uma relação com um elemento prévio ao discurso, não sustentado pelo sujeito, não submetido à discussão, já esquecido em sua origem (ORLANDI, 2004, p. 47) que funciona no visto e também no dito que essa imagem figura.

Nesse sentido, o pré-construído é um efeito que demonstra que aquilo que uma imagem constrói não advém de um sujeito idealista e intencional, fonte do sentido, dono do dizer e do ver, responsável pelo representável, mas de um sujeito atravessado pela linguagem em que o já-visto e o já-dito governam o dizer e o ver.

Assim, tomando este cartaz um operador de memória há alguns elementos aí significando. Destaco, em minha leitura, três ordens: a das cores, a da ausência do corpo subjetivo humano (ou a desencarnação do corpo real) e a da enunciação - do qual a imagem é o suporte. As cores, presentes nos elementos que designam e simulam o humano, conduzemme a um elemento constitutivo de nossa identidade nacional. Falo aqui da imagem que se segue: 


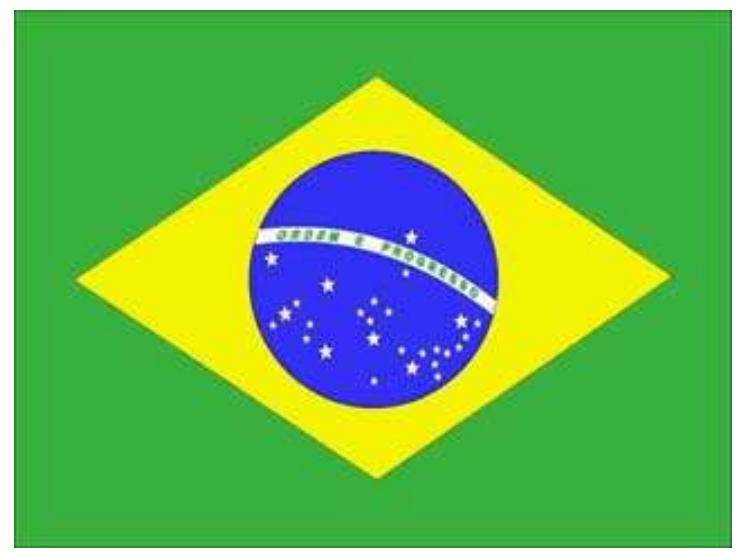

Os três elementos que simulam e corporificam a família estão figurando no cartaz nas cores da bandeira do Brasil. A ciência que estuda as cores, a colorimetria, faz uma distinção clássica que aprendemos nas aulas fundamentais de Artes: as cores primárias e as cores secundárias. As cores primárias, ou as cores primeiras, estão presentes no cartaz colorindo dois grandes cavaletes que representam a figura dos pais. Assim, temos o pai representado pelo azul (cor da concentração e da mente - da razão) e a mãe pelo amarelo (cor suave e alegre que simboliza o otimismo - o sensível).

Da junção dessas duas cores primárias (tal qual a junção entre pai e mãe), temos o nascimento de uma nova cor que designa a figura do filho. O filho é representado pelo cavalete menor na cor secundária verde (formada da mistura entre o azul e o amarelo) que simboliza o equilíbrio, a estabilidade, a capacidade de cura e o ensino. Considero que as cores identificam objetos, estabelecendo aqui uma relação semiológica não só com um símbolo nacional, mas com o corpo familiar.

Ao contrastarmos as cores que representam no cartaz a figura da família, com as cores da bandeira do Brasil, é possível construir algumas analogias: a circunferência da bandeira (em azul - simbolizando o céu) mostra tão facilmente o lugar central do patriarcalismo em nossa história; o amarelo (na bandeira um losango, que representa a riqueza mineral do solo) o entorno materno e feminino no mundo. Da junção do azul e do amarelo obtém-se o verde (a cor mais representativa da bandeira - simbolizando a pujança de nossas matas).

É interessante notar que o verde, ao indicar o lugar do filho, e sendo associado às matas, convoca o mistério e o mítico das florestas, a riqueza que isso constitui e a dificuldade de nossos tempos em não só preservar "o verde", mas também o desafio de saber o que fazer com ele. O que podemos e devemos fazer para o bem dos filhos da nação?

Com relação ao que chamei de a "ausência do corpo subjetivo humano" gostaria de destacar que a família, que figura no cartaz, não é representada por aquilo que singulariza o vivente: a forma, a silhueta do corpo. Não temos aí o corpo de um sujeito, mas a presença de um objeto de uso da escola: um cavalete, objeto que sustenta quadros tanto para a escrita quanto para o desenho.

Faço-me aqui duas questões: por que a ausência de uma figura corporal humana? Por que a presença de um objeto da escola para representar e significar a família? Para além de uma resposta autoritária, verdadeira, vejo aí um desejo dessa escola. De fato, identificar a família como um objeto do universo escolar implica a vontade de se ter a família presente na escola. Tão presente que ela passa a ser um objeto familiar, comum no dia-a-dia.

No entanto, o interessante aqui é a forma como a família é representada: um cavalete, um objeto que não tem vida, que serve para sustentar um quadro. O corpo humano (essa carne

\begin{tabular}{|l|l|l|l|r|r|}
\hline Interfaces da Educ. & Paranaíba & v. 2 & n. 5 & p.5-23 & 2011 \\
\hline
\end{tabular}




\section{INTERFACES DA EDUCAÇÃO}

que nasce, vive, cresce, fica doente, envelhece e morre) aparece instrumentalizada pela escola. O desenho, ao dar identidade para família, já demonstra o modo como essa pode ser acolhida pela escola: um suporte (tal qual o cavalete) na educação dos filhos.

Os cavaletes, ao representarem a figura da família, uma família nacional, inscrita e identificada nas cores da bandeira do Brasil, permitem-me falar no corpo como um discurso. A ausência do corpo subjetivo e a presença do corpo objeto, atestam a desencarnação do real. Isso faz com que o corpo da família se torne um corpo imaginário, um corpo-objeto próprio da escola. Se o corpo real (o meu, o seu, o do outro) é o lugar do instável, do imprevisível, o corpo desencarnado é aquele projetado, calculado, desejado pela própria escola. De fato, temse aqui a metamorfose do corpo da família. Um corpo normalizado, pois muitas vezes o corpo familiar, principalmente na conjuntura de hoje, tem sido uma fábrica de anormais, indisciplinados, enfim, sujeitos monstruosos.

Em uma alusão à literatura, sobretudo a Franz Kafka (1997), em A Metamorfose, na bela passagem que abre o livro "Quando certa manhã Gregor Samsa acordou de sonhos tranqüilos, encontrou-se em sua cama metamorfoseado num inseto monstruoso" ( p. 7), eu diria que transformar o corpo humano, o lugar mais familiar do sujeito, em um objeto escolar, é de certa forma transformar a família em uma coisa, identificá-la em suporte de quadros que a escola quer sustentar.

A terceira ordem da análise remete-me à imagem da escrita ${ }^{7}$ que o cartaz sustenta. A imagem das letras forma um enunciado que, segmentado, permite escutar um discurso que o atravessa. Assim, apresento a figura, na intenção de reconstruir o trajeto do dizer, que ao se imprimir na imagem, abre uma dimensão entre o passado e o futuro, permitindo a rememoração. Vejamos:

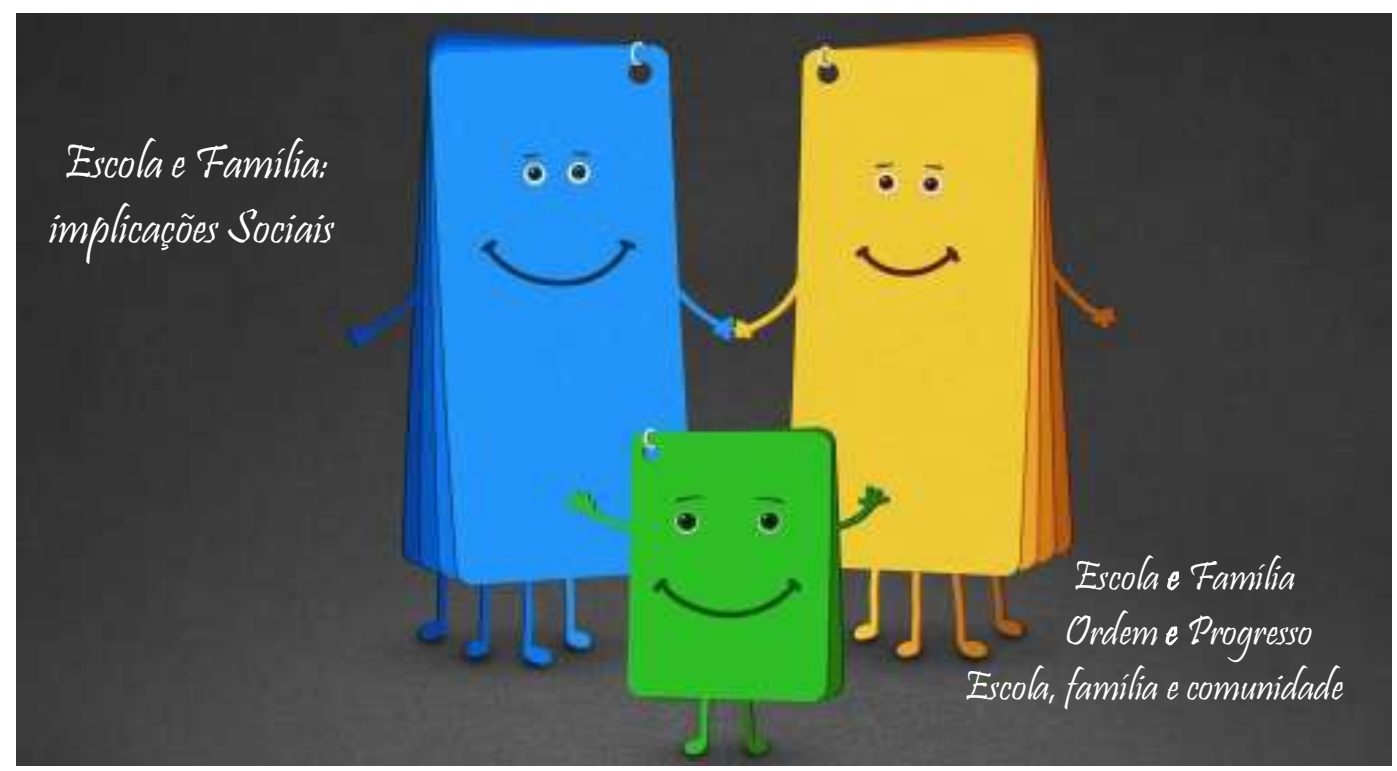

Um modo de pensar o enunciado "escola e família", aqui segmentado, cuja voz ecoa um discurso transverso, um sítio de significância que inscreve "escola e família" como

\footnotetext{
${ }^{7}$ Chamo a atenção aqui para a formulação "imagem da escrita". Muito mais que letras grafadas em um cartaz para o simples registro de um enunciado, a escrita aí tem uma dimensão de imagem. Ela funciona como uma imagem da escritura.
}

\begin{tabular}{|l|l|l|l|l|l|}
\hline Interfaces da Educ. & Paranaíba & v. 2 & n. 5 & p.5-23 & 2011 \\
\hline
\end{tabular}




\section{INTERFACES DA EDUCAÇÃO}

objetos que se reúnem e se atravessam, é o conceito de polissemia (deslocamento, ruptura do processo de significação) e o de paráfrase (retorno aos mesmos espaços do dizer) de Orlandi (1999, p. 36). Eles são o índice da historicidade dos processos discursivos. Observemos, então, os enunciados em relação:

Escola e Família

\section{[ : ] IMPLICAÇÕES SOCIAIS}

Ordem $\underline{\mathbf{e}}$ Progresso

Escola, família e comunidade

O enunciado "escola e família" tem em si uma memória. O que me permite dizer isso é o trajeto de leitura que a imagem dá a fazer, já que ela não é nem opaca e nem muda. De fato, o imaginário não encontra nas imagens sua raiz profunda, sua causa de constituição. Como diz Parente (1993, p. 29) "É a linguagem que faz da imagem um objeto, e do olho um sujeito [...]. Se a imagem se torna um objeto, é para melhor falar a linguagem que se lhe impõem, e que diz: eis meu corpo (realidade empírica ou transcendental)".

Esse enunciado é dito com palavras que já foram ditas. Ao repeti-las, produz-se o novo, o possível e também o diferente. Digo isso porque o enunciado "escola e família", tal qual o enunciado "ordem e progresso" dá-nos a impressão de estarmos dentro de uma história e de um mundo conhecido: "independência ou morte", "diga ao povo que fico", "pão e circo". O que aqui funciona é a imagem enunciativa. A versão que ficou. Ou como diz Orlandi (1993, p. 13) "São espaços da identidade histórica: é a memória temporalizada, que se apresenta como institucional, legítima".

Analisando os enunciados "escola e família" e "ordem e progresso" é possível observar que a similitude entre eles é sustentada pelo efeito de sentido que a marca lingüística e produz. O "e", quinta letra do alfabeto latino, marca sintática de junção, está carregado de sentidos implícitos. Há uma força que faz "ordem" ser articulada a "progresso", da mesma forma que "escola" a "família". Assim, "escola e família", "ordem e progresso" estão regidos por uma memória social que não nos faz perguntar pelo sentido. Essa força de junção é carregada de implícito. Ela é índice da interpretação.

Nessa direção, chamo a atenção para outro enunciado que a esses dois se reúne. Tratase de uma formulação retirada de uma propaganda veiculada no jornal Folha de São Paulo, de sexta-feira, 28 de maio de 2010. Reafirma-se aqui o lugar de análise que tenho procurado sustentar: não apenas um efeito do já-dito, mas também do já-visto, pois a imagem que estrutura o cartaz se atualiza na propaganda impressa no jornal. Vejamos a propaganda:

\begin{tabular}{|l|l|l|l|l|l|}
\hline Interfaces da Educ. & Paranaíba & v. 2 & n. 5 & p.5-23 & 2011 \\
\hline
\end{tabular}




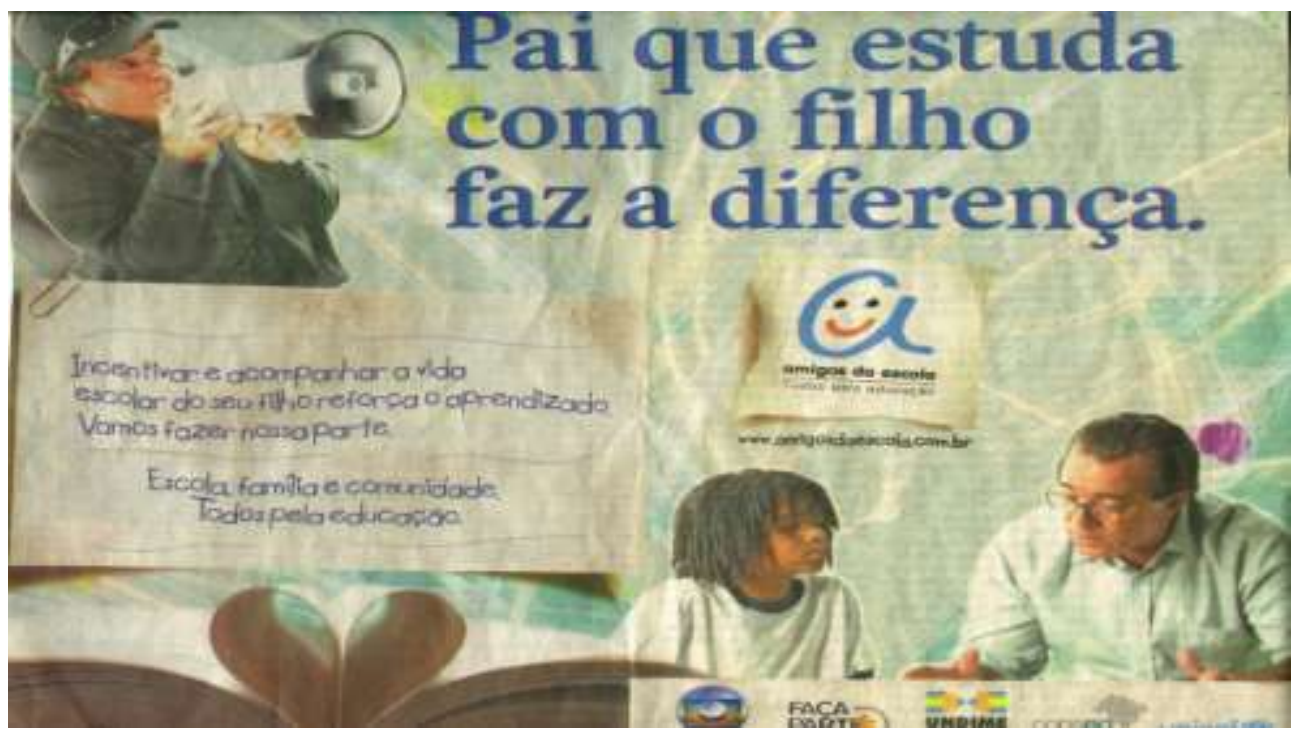

Peça de publicidade em um veículo de comunicação, esta imagem promove uma campanha há muito tempo em circulação no Brasil, por iniciativa de uma ONG. Ressalto nessa imagem dois enunciados: "Todos pela educação" e "Escola, família e sociedade". ORLANDI, (2004, p. 153), ao analisar a formulação "Todo aluno da escola", cuja versão atual pode ser lida como "Todos pela educação", aborda o problema da quantidade.

A quantidade, o todo social, supõe uma concentração de cidadãos no mesmo espaço de vida. Ela é um elemento estruturante das relações sociais. Ao circular o enunciado "Todos pela educação" pressupõe-se que alguns estão a favor da educação enquanto outros estão contra. Portanto, não há consenso, ou seja, a preocupação com a educação não é um sentido partilhado, aceito por todos socialmente. Se há fratura, o que esta permite escutar?

A meu ver, que o problema da quantidade tem sempre sido tratado como uma questão administrativa, de números e de estatística. Além disso, que o problema da não aprendizagem das crianças (portanto de uma falta na relação com o saber) está no fato de os pais não estudarem com os filhos. Há pais contra a educação. Há um movimento tentando levar o que está fora para dentro da escola e isso demonstra que a família, na figura dos pais, tem sido esse "fora" da escola.

$\mathrm{Na}$ leitura dessa propaganda interessa-me diretamente o enunciado "Escola, família e comunidade". Ele está em uma relação parafrástica com os enunciados "escola e família" e "ordem e progresso". O enunciado "escola e família" ao deslizar para a formulação "ordem e progresso" atualiza a memória de um modelo social do Brasil: uma industrialização tardia (daí a necessidade de progresso) e o regime militar que a sociedade foi submetida. Entretanto, esse deslize, permite-me falar de um projeto no qual não só a escola, mas também a família estiveram voltadas: a necessidade de produzir e de manter uma sociedade da disciplina, da repetição, da reprodução.

Para uma família da moral, da ordem e dos bons costumes uma escola como reformatório, como prisão (eis o léxico de nossa escola: grade curricular, disciplinas, prova) e uma escola como fábrica (com o conhecimento tratado como uma linha de montagem: segmentado, fragmentado).

Quando articulamos os enunciados "escola e família", "ordem e progresso" e "escola, família e sociedade" o que podemos escutar é uma re-significação do modelo de sociedade que vivemos. Não apenas a sociedade da "ordem e progresso", mas a sociedade que busca

\begin{tabular}{|l|l|l|l|l|l|}
\hline Interfaces da Educ. & Paranaíba & v. 2 & n. 5 & p.5-23 & 2011 \\
\hline
\end{tabular}




\section{INTERFACES DA EDUCAÇÃO}

uma comum-unidade, viver como comunidade. Há aqui um cultural que assimila a sociedade.

Rodriguez-Alcalá $^{8}$ (2008, p. 167) diz que etimologicamente o termo comunidade, nas línguas neolatinas, pode ser referido ao "comunitas" do latim, definido como "o grupo que tem vínculo em comum". Esse vínculo em comum, essa "comum-unidade" é a busca de uma homogeneização e a exclusão de qualquer desacordo entre os membros grupo. No projeto de uma sociedade comunitarista, a escola e a família estão a serviço de uma sociedade que partilha as mesmas tradições, símbolos, modo de pensar, de sentir, de falar e de viver. De fato, uma sociedade que pela sua comum-unidade institui o individual. Uma sociedade com um cultura comum, com um conjunto de saberes comuns, em que os sujeitos precisam desenvolver habilidades e performance adequadas.

Entretanto, a questão mais interessante, mais inteligente, eu diria, a ser observada a partir dessas considerações é o que o rege, no cartaz do evento, o enunciado "escola e família". Se nos reportarmos à figura (o cartaz do evento) é possível notar que esse enunciado é regido por outra expressão. É isso o que me dá a pensar a pontuação, a sintaxe da frase. A formulação "escola e família", atravessada pelos dois pontos, encontra a expressão "implicações sociais". Os dois pontos, enquanto sinal de pontuação, são a marca de uma mudança de foco, de uma explicação que rege o sentido desses termos reunidos, em junção.

Assim, considerar "escola e família" da perspectiva "das implicações sociais", tendo em vista as condições de produção da sociedade brasileira, é um movimento instigante. Ao invés de seguirmos o discurso encantador, que circula em nossa sociedade, ou seja, o de levar para dentro da escola o que está fora dela (e isso claramente diz respeito à família e à comunidade), levemos o que está dentro da escola para fora, ou seja, para a sociedade. Dessa forma, saímos do funcionamento que faz a escola ser um problema para si mesma. A escola não é um problema da escola, ela é um problema da cidade.

Com relação à família, e escutando aqui a ordem do privado que lhe é constitutiva, levar o seu interior para fora, para o social, significa abri-la à pluralidade, ou seja, há a família nuclear, conjugal (pai, mãe e filho), que constitui as famílias (um conjunto, uma casa, um grupo, parentes, amigos), mas para vivermos em sociedade, é necessário que existam outros laços além dos da consanguinidade. Como salienta Roudinesco (2004) a família não está ameaçada pela modernidade. À diferença da família tradicional, as novas famílias são um movimento que compõem, recompõem e constituem os sujeitos de sexo diferente, do mesmo sexo, que integram os que não têm a filiação biológica, que integram os bastardos, abrindo-se para a ciência quando o corpo não consegue responder ao sonho de ser pai e mãe.

É levando aquilo que é do universo interior para o social que "escola e família", nas condições de produção da sociedade brasileira, poderão construir laços sociais, um novo "esprit de corps", buscando repensar e transformar a ordem da sociedade capitalista em que vivemos: uma sociedade vertical (sociedade de classes) e uma sociedade horizontal (em que as relações de lugar prevalecem).

Pensar a "escola" e a "família" a partir da "implicação social" exige que nos voltemos para o interior da escola e da família, para aquilo que as une, isto é, a educação. Proponho, assim, como gesto de análise, a leitura do fragmento de um filme veiculado no ano de 2008 o "Entre les murs", tradução brasileira "Entre os muros da escola".

\footnotetext{
${ }^{8}$ Cito aqui o texto elaborado por Carolina RODRIGUEZ-ALCALÁ, no Projeto Cael, Labeurb-Unicamp, Relatório Final (processo Fapesp 2004/077340). Um artigo referente a esta pesquisa pode ser encontrado na seguinte publicação: ORLANDI, E. P. (Org.). Discurso e políticas públicas urbanas: a fabricação do consenso. Campinas, Editora RG, 2010.
}

\begin{tabular}{|l|l|l|l|l|l|}
\hline Interfaces da Educ. & Paranaíba & v. 2 & n. 5 & p.5-23 & 2011 \\
\hline
\end{tabular}


Inspirado na obra "Entre les murs", de François Bégaudeau, livro publicado na França em 2006, pela editora Gallimard, este filme, de Laurent Cantet, ganhou as telas em 2008 e também o "Palma de Ouro", no festival de cinema de Cannes. Diferente dos filmes produzidos em Hollywood, principalmente aqueles cuja temática é a educação, (como não se lembrar aqui dos clássicos: "Dead Poets Society - Sociedade do Poetas Mortos", de 1989, com Robin Willians; "Lean on me - Meu mestre, minha vida", de 1989, com Morgan Freeman; "Mona Lisa Smile - O Sorriso de Mona Lisa", de 2003, com Julia Roberts; do francês "Les plus beau métier du monde - Nosso professor é um herói", com Gérard Depardieu, de 1996), em que os professores, sozinhos, transformam a escola, este filme segue uma outra via. $\mathrm{O}$ autor participou da elaboração do roteiro e viveu o intérprete principal do filme, o professor François Marin.

"Entre os muros", título do livro e do filme, tem como cenário uma escola, um colégio do 20éme arrondissement, um bairro da periferia de Paris. O filme, um misto de ficçãodocumentário, conta com a participação de alunos que não são atores de formação. Assim, o expectador acompanhará durante as duas horas do longa-metragem o cotidiano do ano escolar da turma do professor Marin que ensina o francês. A história pedagógica é atravessada por momentos de tensão, de confrontos com a juventude, com o imprevisto, com a intolerância, com o choque de culturas.

Deleuze (1992, p. 69), refletindo sobre o cinema, diz que uma imagem nunca está só. Para ele

O que conta é a relação entre imagens. Ora, quando a percepção se torna puramente óptica e sonora, com o que entra ela em relação, já que não é mais com a ação? A imagem atual, cortada em seu prolongamento motor, entra em relação com uma imagem virtual, imagem mental ou em espelho.

Tomo assim, este filme, uma imagem em movimento, funcionando como um espelho. Ele me permite pensar na presença da escola e da família no espaço da tela. Estamos assim, por conta das condições de produção do filme, um documentário-ficção, em uma relação com o sujeito e com o sentido, permeado pela narrativa, pela câmera, em um cenário, e com uma voz que os corpos-atores devem responder e sustentar.

Interessa-me, particularmente, três momentos da temporalidade da narrativa fílmica: a reunião do conselho de disciplina da escola (com a presença dos membros do conselho, da representante da família e do aluno problema - a personagem Souleymane); o momento de concluir o ano letivo, devendo os alunos responder ao professor, na sala de aula, o que de importante aprenderam no decorrer do período letivo; e, o diálogo entre uma aluna e o professor sobre a questão da aprendizagem. Aproprio-me do diálogo entre Henriette e François Marin para com este refletir sobre o processo de escolarização. A letra $\mathrm{H}$ refere-se Henriette e as letras FM a François Marin.

No filme, no término da aula:

\section{H: Professor?}

FM: O que houve?

H: Eu não aprendi nada.

FM: Por que está dizendo isso? Não é verdade.

H: Agora a pouco todo mundo disse que tinha aprendido alguma coisa. E me comparando com eles não aprendi nada.

FM: Aprendeu tanto quanto eles. Também tiveram que se lembrar. Não é fácil nos lembrarmos do que aprendemos.

\begin{tabular}{|l|l|l|l|l|l|}
\hline Interfaces da Educ. & Paranaíba & v. 2 & n. 5 & p.5-23 & 2011 \\
\hline
\end{tabular}


H: Mas eu não compreendo.

FM: Você não compreende. O que quer dizer com isso?

H: Não entendo o que fazemos.

FM: Em francês?

H: Em tudo!

FM: Não pode dizer que não aprendeu nada no conjunto das disciplinas. Isso não é verdade.

H: Não quero ir para o curso profissionalizante.

FM: Mas não vale a pena pensar nisso agora. Agora você vai passar para o nono ano. Você ainda tem muito tempo para pensar no que vai fazer no futuro. Não é certo que você tenha que ir para um curso profissional. Isso vai depender dos seus resultados no próximo ano.

H: Mas eu não quero.

Esse diálogo entre o professor e a aluna surpreende. Ela permanece um ano na escola e diz: "Eu não aprendi nada". Questionada sobre o que não aprendeu, no conjunto das disciplinas, a aluna sustenta "Em tudo". Essa fala nos coloca frente a uma questão interessante: ao reverberar, enquanto sentido, nos muros da escola, a sede do conhecimento, o que significa "não aprender nada"? Qual é o "não-saber" que estava em companhia da aluna? Essas duas questões me incitam a pensar no lugar do professor (aquele que ensina) e no do aluno (aquele que aprende) e na aprendizagem.

Nascendo no seio da família, portanto, fruto da autoria dos pais, a criança é uma obra que figura no mundo, devendo refletir não só os seus "autores", mas também desempenhar no futuro uma "função-autor". Recebendo dos pais um nome, laço significante que faz do sujeito um "eu", um corpo nominado, a criança para ter um lugar no mundo, adentra em uma rede de sentidos, que precede o seu nascimento. Enquanto um organismo vivo, pura carne, a criança para viver se encontra, se choca com a linguagem que a precedeu. A subjetividade humana não está dada ao nascer. É no encontro com a alteridade que um sujeito passa a viver.

A família, lugar princeps da estruturação subjetiva, caldeirão da vida social, necessita do auxílio de outras instituições e pessoas para que o ser, confiado a ela, viva em sociedade. Neste sentido, cabe não só à família, mas também ao Estado, zelar pelos filhos. A escola advém, assim, como um dispositivo, um espaço discursivo da escolarização. Cabe a ela promover relações de sentido, em relação aos sujeitos a ela confiados, de modo que possam responder no mundo àquilo que se espera de um cidadão: um sujeito (letrado) de direitos e de deveres.

A escrita entra aqui como ferramenta fundamental na produção do sujeito escolarizado. Como diz Pfeiffer (2003, p. 116) a escrita funciona no espaço escolarizado como um divisor de águas, instaurando para o sujeito, um lugar de evidência para seu estado de barbárie quando não conformado ao modelo canônico da escrita-escolarizada - a urbanidade da língua.

Essa barbárie da qual fala a autora conduz-me àquilo que Marisa Vieira, em sua tese de doutorado, nomeia como a metáfora fundadora do referente analfabeto. A isto acrescento, ainda, o sujeito que vive, mesmo passando pela escola, as contendas com a escrita. Como aponta Silva (1998, p. 200) enquanto no Ocidente a leitura e a escrita sempre foram instrumentos para a formação do homem político, cidadão do Estado Moderno, nas condições de produção da história do Brasil, o domínio da escrita (de uma língua escrita estrangeira), significa a possibilidade de ser homem, de ser sujeito civilizado. 
Assim, partindo de um fragmento de uma carta ${ }^{9}$ de 1549 , de Manoel de Nóbrega, para o Dr. Navarro, a autora trata uma questão interessante, que abordarei na relação com o "nãosaber", o "não-aprender". Eis o recorte da carta do jesuíta:

Fallarei agora da porta que Nosso Senhor se dignou de abrir nestes poucos mezes
para escolher dentre elles os que foram predestinados [...] Convidamos os meninos a
ler e escrever e conjuntamente lhes ensinamos a doutrina cristã [...] De muitas partes
somos chamados, para irmos ensinar as cousas de Deus e não podemos chegar,
porque somos poucos; e certo, creio que em todo mundo não se nos depara terra tão
disposta para produzir o fructo como esta, onde vemos almas parecerem por não
poder remedial-as: em falta, vamos lhes accendendo a vontade de ser christãos, para
se morrerem, neste comenos, emquanto dura o catechismo, delles Deus haja
misericordia. Aos que amam a Deus e desejam a sua gloria não sei como lhes soffre
a paciencia de não se embarcarem logo e virem cavar nesta vinha do Senhor que tão
espaçosa é, e que tão poucos operarios possue. Poucas letras bastariam aqui,
porque tudo é papel branco e não ha que fazer outras cousa, sinão escrever á
vontade as virtudes mais necessarias e ter zelo em que seja conhecido o
Creador destas suas creaturas. (SILVA, 1998, p. 200).

A leitura desta carta, sobretudo do recorte em destaque, em que aparece a expressão "Poucas letras bastariam aqui, porque tudo é papel branco [...]" produz o sentido de que nas pessoas que habitavam o Brasil não havia nada a ser decifrado. Como diz a autora

A alteridade para o europeu apresentava-se, imaginariamente, como o vazio, algo a ser plenamente saturado. B-a-bá... B-e-bé... Nessa cadeia significante, começa-se a soletrar um sujeito e um sentido que o significante já antecipara; começa-se a sóletrar uma história que um discurso já escrevera. (SILVA, 1998, p. 2002).

Essa metáfora do papel branco, do vazio que precisa ser saturado, faz-me pensar no "nada-saber", em uma relação em que, por não "saber" escrever, ao homem é negada a sua humanidade. Na história do Brasil, os que aqui habitavam o território, antes de nós, eram para o colonizador, uma imagem do vazio, da ausência das letras, fazendo do homem "um texto, um livro, um discurso" em branco.

A entrada do homem no mundo do discurso, na escola, marca o sujeito, que terá de ocupar um lugar de enunciação dentro do funcionamento de uma língua escrita enquanto sujeito letrado. A sua cidadania só será atestada se um papel em branco for preenchido por letras, devendo o sujeito constituir-se em autor, pois a escrita é um processo que envolve a sociedade.

Foucault (1997) diz que a noção de autor constitui um forte momento de individualização na história das idéias. Abordando a "função autor" o filósofo vai dizer que ela está ligada ao sistema jurídico e institucional que encerra, determina, articula o universo dos discursos (p. 56). O autor é índice das possíveis funções do sujeito, ele é o princípio de agrupamento do discurso.

No entanto, na perspectiva discursiva, esse princípio de "agrupamento do discurso" é um princípio de textualidade e um processo na textualidade. Como salienta LagazziRodrigues (2006, p. 93)

Assumir a autoria colocando-se na origem de seu dizer é fazer do dizer algo imaginariamente 'seu', com 'começo, meio e fim', que seja considerado original e

\footnotetext{
${ }^{9}$ Carta escrita em 1949, ao Dr. Navarro, mestre de José de Anchieta, em Coimbra, Portugal, dando visibilidade ao objeto da ação evangelizadora da Companhia de Jesus no Novo Mundo.
}

\begin{tabular}{|c|c|c|c|c|c|}
\hline Interfaces da Educ. & Paranaíba & v. 2 & n. 5 & p.5-23 & 2011 \\
\hline
\end{tabular}


relevante, que tenha clareza e unidade. É, dessa maneira, responsabilizar-se pelo que foi dito e pelo que foi silenciado.

O autor, assim, torna-se visível e, com isso, identificável e controlável. A autoria é uma prática de textualização e o grande desafio é praticá-la no cotidiano das linguagens. Para a autora "Uma prática cotidiana, no sentido de um investimento constante, não apenas nos espaços institucionalizados" (idem, p. 99). É preciso ousar ser autor. Dizer, mas reelaborar na injunção da unidade, da identidade.

Esse processo toca fundamentalmente a manutenção dos processos identitários, de sujeitos que se textualizam no espaço discursivo da família e da escola. A família, lugar de exercício da subjetividade, da educação para o afeto, do contato com o legado dos antepassados, que acolhe e cuida da infância e da adolescência tem que lidar com o enfrentamento do mundo como ele é. Nesse processo a educação é puro mistério e acidente. Assim, é não se isolando da sociedade, se fechando com medo da diferença, da violência, que encontraremos meios, enquanto sociedade, para viver com ético e capacidade de cuidar de si mesmo e de ver o outro como si mesmo.

À escola, a tarefa é de, ao se abrir para a sociedade, ou seja, de levar o dentro para fora de si, tratar o conhecimento, o legado da humanidade que ela administra, como um processo e não como um produto guardado em seus muros. Isso implica em não mais moldar o cidadão negação de que no Brasil não nascemos cidadãos, mas precisamos ir à escola para assim o sermos.

Sair dos muros da escola é ter que se confrontar "com a rua, com seus sujeitos, seus modos de existência, de resistência e de saber, de arte e de cultura. Que não é a letrada mas é, existe em suas outras formas. (cf. ORLANDI, 2004, p. 153). Passar para o outro lado implica em viver, em experimentar, em saber a cidade. De fato, abrir-se para a compreensão de que o conhecimento "não é um conteúdo guardado na escola; ele está no mundo (na cidade)em seu real, na relação que o sujeito estabelece com o entorno em que vive (ORLANDI, 2004, p. $155) "$.

Esse processo transforma a nossa relação com a escrita, com o mundo. Já que passar pela escola pode implicar muito mais que saber ler e escrever, ou seja, ser ALFABETIZADO. Há a possibilidade de se viver na condição ou estado de quem sabe ler e escrever. Mas o desafio é que temos pessoas alfabetizadas, e que não vivem no estado ou condição de quem sabe ler e praticar a leitura e a escrita, nas linguagens cotidianas.

A escrita é um produto cultural por excelência, uma atividade do homem sobre o mundo. O livro (o subproduto mais acabado da escrita) é tomado como uma metáfora do corpo humano: fala-se nas 'orelhas' do livro; na sua página de 'rosto'; nas notas de 'rodapé', e o capítulo em latim é a 'cabeça' (cf. SILVA, 1998).

De Lemos (1998, p. 16) diz que há um caráter irreversível da transformação que se opera em nós pelo simbólico. Para a autora

Uma vez transformados pela escrita em alguém que pode ler ou escrever, não é possível subtrairmo-nos a seu efeito, nem concebermos qual é a relação que aquele que não sabe ler tem com esses sinais que, para nós, apresentam-se como transparentes. Ou ainda, não podemos mais recuperar a opacidade com que esses sinais antes se apresentavam também para nós.

Caso isso faz sentido, a gente deve começar a se interrogar sobre o que é ensinar, o que é aprender, quando o que está em jogo é essa transformação pelo simbólico. Precisamos começar a pensar como algo se torna outro ou passa a se apresentar como outro à percepção e

\begin{tabular}{|l|l|l|l|r|r|r}
\hline Interfaces da Educ. & Paranaíba & v. 2 & n. 5 & p.5-23
\end{tabular} 


\section{INTERFACES DA EDUCAÇÃO}

à interpretação, transformando o sujeito em alguém que 'lê', isto é, que vê o que não estava lá, que pode dizer eu sei, eu aprendi.

Retorno aqui ao diálogo do filme "Entre les murs", no qual a aluna surpreende o professor dizendo que passou pela escola um ano todo e nada aprendeu. Esse "não-saber" tem relação com o conhecimento que, circulando no universo escolar, tão naturalizado pelo corpo docente, tão transparente para o professor, não produziu sentido para o aluno. A título de exemplificação, relato uma experiência de quando eu era docente em uma escola pública no Estado de São Paulo.

Minha colega, professora de biologia, ao ensinar aos alunos a composição do sangue humano e tipos sangüíneos, realizou em sala de aula testes de tipagem sanguínea com os alunos, utilizando para furar os dedos de muitos alunos uma mesma agulha. Quando do fim da atividade e, entrando na sala de aula outro professor, que ouviu os relatos animados dos alunos, este, assustado, os interpelou: vocês compartilharam o mesmo material (agulha)? Gritos, choro. Um problema institucional estava criado. Mais do que institucional ele era pedagógico e de saúde pública.

Entrando eu, nesta mesma sala, e vindo falar comigo alguns alunos, eu exclamara: vocês deveriam ter percebido que esse procedimento não deveria ter sido realizado, principalmente do modo em que foi. Uma aluna violentamente proferiu: isso nós sabemos, queremos ouvir de você uma palavra de conforto. Assim, disse: tudo vai ficar bem. É preciso estar atento ao seguinte: há informações circulando sobre o não compartilhamento de materiais que podem vir a ser fonte de contaminação de doenças, entre elas, o vírus HIV. E acrescentei: uma coisa é a informação que circula, outra é essa informação ser incorporada em nós, tornando-se um saber, uma relação com o sentido. Tal qual a personagem do filme, Henriette, que não sabia, portanto estava em uma relação com o "não-sentido", essa era também a posição de meus alunos.

Abordo aqui, portanto, a questão do funcionamento do discurso pedagógico, já que este permite observar, no que diz respeito à identidade, o lugar do professor e do aluno, no que diz respeito ao processo de ensino-aprendizagem. Orlandi (1983, p. 16) destaca como se pode visualizar o funcionamento do discurso pedagógico. Vejamos:

\begin{tabular}{|lllll|}
\hline QUEM & ENSINA & O QUE & PARA QUEM & ONDE \\
$\downarrow$ & $\downarrow$ & $\downarrow$ & $\downarrow$ & $\downarrow$ \\
Imagem do & Inculca & Imagem do & Imagem do & Escola \\
professor & & referente & aluno & $\downarrow$ \\
(A) & & $\downarrow$ & (B) & Aparelho \\
& & Metalinguagem & & Ideológico \\
& & (ciência/fato) & (X) \\
& & & Sede do DP \\
& & & \\
\hline
\end{tabular}

Esta formulação permite-nos observar a relação de sentido entre professor e aluno, no espaço da escola. A imagem do professor, do aluno, do saber e da escola não brota do nada. Há um processo que liga sujeito, discurso e instituição. Opera aqui o imaginário que faz parte do funcionamento da linguagem. Em toda língua, diz Orlandi (1999, p. 40), há regras de projeção que permitem ao sujeito passar da situação (empírica) para a posição (discursiva). O que significa no discurso são essas posições. E elas significam em relação ao contexto sócio-

\begin{tabular}{|l|l|l|l|r|r|r}
\hline Interfaces da Educ. & Paranaíba & v. 2 & n. 5 & p.5-23 \\
\hline
\end{tabular} 
histórico e à memória.

Nesse quadro, é possível notar, que o lugar da posição do professor é o daquele que ensina, que tem uma relação com o saber e é sustentado por uma instituição que lhe outorga transmitir o saber. E aluno? Como a etimologia da palavra diz, o aluno é a-luno, ou seja, sem luz. Cabe ao aluno ser iluminado, tornar-se um sujeito cuja luz do saber, transmitido pelo professor, tira-o da escuridão. A cena educativa de nossa escola é aquela que produz uma pedagogia em que nada falta. Tudo aquilo que é transmitido o aluno não só deve saber, mas também aprender.

Considero, tal qual Pêcheux (1997), que não existe aprendizagem e sim filiação a rede de sentidos. Aprender não é interagir com o mundo, com o outro, dependendo do desenvolvimento das estruturas físicas e mentais do sujeito. Aprender é ter que lidar com a significação do sem-sentido. Ato perigoso, pois o sem-sentido não é estável, coerente e homogêneo.

Isso faz com que a cena educativa seja atravessada pela incompletude. Assim, naquilo que se "recolhe como resultado de "aprendizagem" (as avaliações, por exemplo) pode se descobrir que o que o professor ensina não é aquilo que o aluno aprende, e vice-versa. Falta, como diz Lemos (2007, p. 87), correspondência. Desse modo, quando é que o ato de ensinar poderia despertar um desejo de aprender? Para a autora, quando o que causa no professor o desejo de ensinar, por exemplo, Matemática, é mais a sua relação com a Matemática do que a necessidade de encontrar nos alunos os sinais de confirmação de que sua mensagem em Matemática fora recebida.

E por falar em Matemática é preciso dizer que esta tem muito a nos ensinar sobre a identidade. Isso, quando nos reportamos à teoria dos conjuntos, sobretudo, à noção de intersecção. A noção de conjunto, dizendo muito superficialmente, é uma noção primária que evoca a idéia de coleção, de reunião de objetos de qualquer natureza (pontos de um plano, números, funções, etc) que são por definição os elementos do conjunto. Chamamos de intersecção dois conjuntos $\mathrm{E}$ e $\mathrm{F}$, notados $\mathrm{E} \cap \mathrm{F}$, os elementos dos conjuntos pertencem ao mesmo tempo a $\mathrm{E}$ e $\mathrm{F}$, conforme a representação gráfica que se segue:

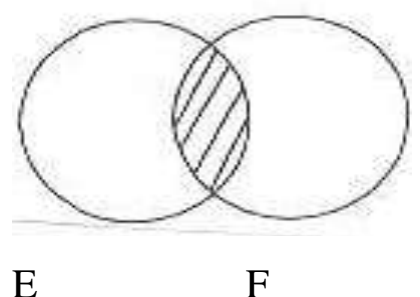

$\mathrm{Na}$ intersecção há um espaço entre os conjuntos que faz com que o elemento de um conjunto e de outro se recubram, sem sabermos distinguir o que é do domínio de E e o que é de F. Esses dois conjuntos distintos se pertencem mutuamente. Esse encontro faz com que os conjuntos não estejam unidos completamente, porque alguma coisa falta a cada um deles. E se há falta, logo a identidade, o idem, o mesmo, de cada um, é inconsistente.

Lendo a intersecção como um lugar que faz o conjunto $\mathrm{E}$ (escola) se encontrar com o conjunto $\mathrm{F}$ (família), o que se põe em jogo não é a união entre escola e família, para se solucionar os problemas no interior da escola, na sociedade. O que está em jogo é, justamente, a diferença da escola unida à diferença da família. $\mathrm{O}$ encontro entre os diferentes é que faz existir o efeito sociedade, materializado na história. É isso que deve estar implicado quando

\begin{tabular}{|l|l|l|l|l|l|}
\hline Interfaces da Educ. & Paranaíba & v. 2 & n. 5 & p.5-23 & 2011
\end{tabular} 
falamos do social: uma escola e uma família cujo encontro convida ao desconhecido, aos laços com a alteridade.

Um desconhecido que pode vir a transformar uma ordem socialmente conhecida e vivida por cada um de nós. A ordem de uma sociedade vertical, de classes, em que há uma ilusão de que o sujeito pode ser incluso no processo do qual ele está excluído, ou seja, subir na vida, enriquecer, seja pelo esforço próprio ou pela educação. E a hoje ordem horizontal, em que o sujeito ou está dentro ou está fora da sociedade. Um desconhecido capaz de reanimar os laços sociais e escrever outra história, já que somos sujeitos históricos, simbólicos e sociais.

\section{Considerações Finais}

No processo de escritura deste texto, ressoava em minha memória, sobretudo a de minhas leituras, aquilo que está registrado no prefácio de uma obra clássica da filosofia "Diferença e Repetição" -, de Gilles Deleuze. Eu me recordava diretamente do fragmento em que Deleuze diz que o pensamento moderno nasce da falência da representação e da perda das identidades.

É, assim, com a voz do filósofo, que inicio o meu momento de concluir, ou seja, aquele de sofrer os efeitos de um percurso. Diz Deleuze:

O mundo moderno é o dos simulacros. Nele o homem não sobrevive a Deus, nem a identidade do sujeito sobrevive à identidade da substância. Todas as identidades são apenas simuladas, produzidas como um 'efeito' ótico por um jogo mais profundo, que é o da diferença e da repetição (1988, p. 16).

Trago aqui a queda da representação de uma identidade, pois foi isso que me deu a pensar o tão inteligente cartaz produzido para divulgar um evento. Não vejo ali a estabilidade e a evidência de uma imagem, que faz com que coisas representem sujeitos. Vi a desrealização e a desencarnação dos corpos, cores corporificando o corpo da nação, a família em um quadro estático, sustentado por um cavalete no interior da escola.

Essa leitura - e o risco que com ela eu corro -, porque posso ser considerado uma pessoa indelicada, eufemismo de grosseiro, ao analisar imagens e, dentre elas, a do cartaz do evento em que sou convidado a falar - é meu gesto de escuta da formulação que sustenta a minha reflexão: "Escola e Família: implicações sociais".

Este enunciado, ao figurar em uma imagem, não é simples enunciação. Ele também não é um enunciado temático (tema como um conteúdo dado a pensar), ou o gesto pensado e calculado de um grupo de pessoas na organização de um evento. A leitura que fiz dele não é aquela que ainda faz a escola, que busca no conteúdo do que é trabalhado em sala de aula, o que autor quis dizer.

A seleção da imagem que sustenta a divulgação deste evento é um gesto político. E por quê? Pela justa razão de que, como somos sujeitos de linguagem, e o nosso lugar de significação, de identidade, é fruto da memória, do esquecimento, daquilo que "fala antes, depois e independentemente" do sujeito. Está ai a ideologia, a exterioridade, o lugar de manutenção do eu.

Mas posso dizer que este sentido que articulo estava silenciado e que ao ver a imagem eu pude perceber isso. A confecção do cartaz, o seu modo de sustentar a linguagem, passou isso para mim. Assim, ao invés de ficar na certeza da imagem, daquilo que ela simplesmente fazia ver, eu decidi tentar compreender que sentido poderia estar ali, fazendo daquele quadro, (e veja que a cor do quadro é idêntica à cor do quadro negro da escola) um discurso.

\begin{tabular}{|l|l|l|l|l|l|}
\hline Interfaces da Educ. & Paranaíba & v. 2 & n. 5 & p.5-23 & 2011 \\
\hline
\end{tabular}


Nesse processo, fui seduzido pela imagem das letras, que iluminando os desenhos, dizia: "escola e família: implicações sociais". Foi segmentando o enunciado, trabalhando com a polissemia das palavras, que pude, ao ver a sintaxe, pensar na forma que a palavra "implicações sociais" produzia, enquanto formulação - o momento como diz Orlandi (2001, p. 9), "que a linguagem ganha vida, que a memória se atualiza, que os sentidos se escondem, que o sujeito se mostra (e se esconde)". A formulação é um momento de definição, em que corpo e sentido se atravessam.

Assim, falar de escola e família, da perspectiva das implicações sociais, sobretudo considerando a disjunção entre esses espaços de discursividade, é abrir uma via para pensar essa sociedade que habitamos, atravessada e constituída pela escrita. Escrita que muitas vezes a escola já dá como pronta para seus alunos, não trabalhando para a assunção da autoria.

A autoria, como diz Lagazzi-Rodrigues (2006, p. 93), "[...] momento em que sujeito e linguagem se constituem ao mesmo tempo, momento em que autor e texto mantêm entre si uma relação necessária" é uma dimensão importante a ser considerada, pois é uma prática de configuração da subjetividade. Prática essa que me faz pensar nos pais enquanto autores dos filhos e, nos filhos, como autores do texto que é a cidade, a sociedade.

Mas, para nosso horror e mal-estar, o que estamos vendo nas obras produzidas pelos pais e no texto da cidade é a tamanha dificuldade dos sujeitos em tomar decisões e analisar as situações com as quais eles se defrontam, pois nos confrontamos com sujeitos desarrimados, gravitando em torno de um objeto que não tem estilo. A alteridade, como diz Melman (2003, p. 112), continua sendo uma dimensão que ainda recusamos em nossas reivindicações de comunhão e de pertença.

É papel da escola e da família zelar para o bem estar das novas gerações. Assim, é saindo de seu interior e se abrindo para a cidade que elas podem contribuir, cada uma a seu modo, como o laboratório político, social e afetivo que são, para mudarmos os trajetos, o percurso que tem feito nosso país, em um mundo que além de não ter espaço para todos, ainda impede que a escória da humanidade possa viver.

Por fim, vale dizer, que os desafios que temos, enquanto sujeitos imersos em famílias e trabalhando na educação, são imensos e inúmeros. O importante é que vençamos a tentação de nos ajustarmos a um modelo, seja ele de justiça ou de verdade, procurando adaptar a escola à família, vice e versa e, as duas, à estrutura social em que vivemos. E um caminho possível para isso, quem nos dá, é o poema que se segue, o Soberania, de Manoel de Barros.

\author{
Naquele dia, no meio do jantar, eu contei que \\ tentara pegar na bunda do vento - mas o rabo \\ do vento escorregava muito e eu não consegui \\ pegar. Eu teria sete anos. A mãe fez um sorriso \\ carinhoso para mim e não disse nada. Meus irmãos \\ deram gaitadas me gozando. O pai ficou preocupado \\ e disse que eu tivera um vareio da imaginação. \\ Mas que esses vareios acabariam com os estudos. \\ E me mandou estudar em livros. Eu vim. E logo li \\ alguns tomos havidos na biblioteca do Colégio. \\ E dei de estudar pra frente. Aprendi a teoria \\ das idéias e da razão pura. Especulei filósofos \\ $e$ até cheguei aos eruditos. Aos homens de grande \\ saber. Achei que os eruditos nas suas altas \\ abstrações se esqueciam das coisas simples da \\ terra. Foi aí que encontrei Einstein (ele mesmo \\ - o Alberto Einstein). Que me ensinou esta frase:
}




\begin{abstract}
A imaginação é mais importante do que o saber. Fiquei alcandorado! E fiz uma brincadeira. Botei um pouco de inocência na erudição. Deu certo. Meu olho começou a ver de novo as pobres coisas do chão mijadas de orvalho. E vi as borboletas. $E$ meditei sobre as borboletas. Vi que elas dominam o mais leve sem precisar de ter motor nenhum no corpo. (Essa engenharia de Deus!) E vi que elas podem pousar nas flores e nas pedras sem magoar as próprias asas. E vi que o homem não tem soberania nem pra ser um bentevi.
\end{abstract}

\title{
Referencias Bibliográficas
}

BARROS, M. Memórias Inventadas: A Terceira Infância. São Paulo: Editora Planeta, 2008, tomo X, com iluminuras de Martha Barros.

DE LEMOS, C. T. G. Sobre a aquisição da escrita: algumas questões. In: ROJO, R. Alfabetização e Letramento: Perspectivas Lingüísticas. Campinas: Mercado de Letras, 1998.

DELEUZE, G. Diferença e repetição. Tradução Luiz Orlandi e Roberto Machado. Rio de Janeiro: Graal, 1988.

$$
\text { . Conversações. Tradução Peter Pal Pelbart. São Paulo: Ed. 34, } 1992 .
$$

FOUCAULT, M. O que é um autor? Trad. António Bragança de Miranda e António Fernando Cascais. Veja, 1997.

KAFKA, F. A Metamorfose. Tradução e posfácio: Modesto Carone. São Paulo, Companhia das Letras, 1997.

LAGAZZI-RODRIGUES, S. Texto e Autoria. IN: Orlandi, E. P. e Lagazzi-Rodirgues (Org.) Discurso e Textualidade. Campinas: Pontes Editores, 2006, p. 81-104.

LEMOS. M. T. G. Desejo de Educar. In: ETD - Educação Temática Digital, Campinas, v. 8, n. esp., p. 80-89, jun. 2007.

MELMAN, C. O homem se gravidade: gozar a qualquer preço. Entrevistas por Jean-Pierre Lebrun. Trad. Sandra Regina Felgueiras. Rio de Janeiro: Companhia de Freud, 2003.

ORLANDI, E. P. A linguagem e seu funcionamento. Campinas: Pontes, 1983.

Análise de Discurso: Princípios e Procedimentos. Campinas: Pontes, 1999.

(Org.) Discurso fundador: a formação do país e a construção da identidade nacional.

Campinas, SP: Pontes, 1993.

. Discurso e Texto: Formulação e Circulação de Sentidos. Campinas: Pontes, 2001.

Cidade dos Sentidos. Campinas, São Paulo: Pontes, 2004.

PARENTE, A. Os paradoxos da imagem-máquina. In: PARENTE, A. (Org.). Imagem Máquina: A era das tecnologias. São Paulo: Editora 34. p. 7-33.

PÊCHEUX, M. O Papel da Memória. In: ACHARD, P. [et all.] O Papel da Memória. Trad. José Horta Nunes. Campinas: Pontes, 1999.

O discurso: Estrutura ou Acontecimento. Campinas: Pontes, 1997.

PFEIFFER, C. Definir (,) um percurso. In: ORLANDI, E. P. (Org.) Para uma enciclopédia da cidade. Campinas: Pontes Editora, Labeurb/Unicamp, 2003, p. 105-120.

ROUDINESCO, E. A família em desordem. Rio de Janeiro: Jorge Zahar, 2003

REVUZ, C. "Eu...? Escrever...?...Eu..." Ou como ajudar os formadores a escrever sobre suas práticas. In: Escrita, Escritura, Cidade (II). Escritos, n 7, Labeurb, 2002, p. 21-42.

\begin{tabular}{|l|l|l|l|l|l|}
\hline Interfaces da Educ. & Paranaíba & v. 2 & n. 5 & p.5-23 & 2011 \\
\hline
\end{tabular}


SILVA, M. V. História da Alfabetização no Brasil: a constituição de sentidos e do sujeito da escolarização. Tese de Doutorado. IEL, Unicamp, 1998.

Jornal

FOLHA DE SÃO PAULO. São Paulo, sexta-feira, 28 de maio de 2010, publicidade.

DVD

Entre les murs. Entre os muros da escola. França. 2008. Direção: Laurent Cantet. 150 min. Distribuição: Imovision.

Internet

Cartaz Uems - Disponível em <http://www.uems.br/portal/editais/33_1_14-042010_13_39_35.pdf>. Acesso em: 20 maio 2010.

Bandeira do Brasil

Disponível em: <http://www.inmetro.gov.br/consumidor/produtos/bandeira.asp>. Acesso em: 20 maio 2010. 